\title{
Copper(II) Complexes of 2-(Methylthiomethyl)anilines: Spectral and Structural Properties and In Vitro Antimicrobial Activity
}

\author{
Temitope E. Olalekan, ${ }^{1}$ Denzil R. Beukes, ${ }^{2}$ Bernardus Van Brecht, ${ }^{3}$ and Gareth M. Watkins ${ }^{1}$ \\ ${ }^{1}$ Department of Chemistry, Rhodes University, P.O. Box 90, Grahamstown 6140, South Africa \\ ${ }^{2}$ Faculty of Pharmacy, Rhodes University, P.O. Box 90, Grahamstown 6140, South Africa \\ ${ }^{3}$ Department of Chemistry, Nelson Mandela Metropolitan University, Port Elizabeth 6001, South Africa
}

Correspondence should be addressed to Temitope E. Olalekan; topeolalekan11@yahoo.com

Received 23 December 2013; Accepted 13 February 2014; Published 16 April 2014

Academic Editor: Roman Boča

Copyright (C) 2014 Temitope E. Olalekan et al. This is an open access article distributed under the Creative Commons Attribution License, which permits unrestricted use, distribution, and reproduction in any medium, provided the original work is properly cited.

Copper(II) complexes of 2-(methylthiomethyl)anilines (1a-1f) have been obtained and characterized by elemental analyses, IR, electronic spectra, conductivity, and X-ray crystallography. The complexes (2a-2f) have the structural formula $\left[\mathrm{CuCl}{ }_{2} \mathrm{~L}\right]$ with the bidentate ligand coordinating through sulfur and nitrogen. The single crystal X-ray diffraction data reveal that the copper complex (2f) has a tetragonally distorted octahedral structure with long $\mathrm{Cu}-\mathrm{Cl}$ equatorial bonds. Magnetic susceptibility measurements indicate the availability of one unpaired electron in the complexes and the conductivity measurements in DMF show their behaviour as nonelectrolytes. The solid reflectance spectra and the electronic spectra of the complexes in DMSO were determined. The ligands and their copper complexes were screened for in vitro antimicrobial activity against S. aureus, B. subtilis, E. coli, and C. albicans. The methoxysubstituted complex (2c) showed more promising antibacterial activity against $S$. aureus and B. subtilis than other compounds at the concentration tested.

\section{Introduction}

The alkylthioalkylated anilines have found application as intermediates in production of many organic compounds [1-3] including dyes, rubber, and herbicides [4]. They act as coordinating ligands due to the presence of the aniline nitrogen and the thioether sulfur in their moiety. The hardborderline and soft nature of the nitrogen and sulfur, respectively, in alkylthioalkylated anilines permits the formation of stable complexes between them and metal ions under mild nonextreme reacting conditions. Donor groups commonly found in many known biologically active compounds and ligands used in pharmaceutical synthesis include the nitrogen, oxygen, sulfur, and chlorine atoms. Such biopotent organic compounds with their metal complexes are being explored for their activity against a wide range of microorganisms. Sulfur-containing ligands and complexes have been explored for biological activity and practical application [57]. Some metal complexes of SN ligands were investigated and reported. Copper(II) complexes $\mathrm{CuX}_{2}(\mathrm{~N}-\mathrm{SMe})(\mathrm{X}=\mathrm{Cl}$,
$\mathrm{Br}$ ) obtained from alcohol solution at $0^{\circ} \mathrm{C}$ were not very stable [8]. $\mathrm{Ni}(\mathrm{II})$ complexes of 2-methylthiomethylaniline [8] and 8-methylthioquinoline [9] have the composition $\mathrm{NiX}_{2}(\mathrm{~N}-\mathrm{SMe})_{2} \quad(\mathrm{X}=\mathrm{Cl}, \mathrm{Br}[8] ; \mathrm{X}=\mathrm{Cl}, \mathrm{Br}, \mathrm{I}, \mathrm{NCS}$ [9]). The $\mathrm{Pd}(\mathrm{II})$ and $\mathrm{Pt}(\mathrm{II})$ complexes of these ligands, on being heated in dimethylformamide were S-demethylated to yield the thiolo-bridged complexes $\mathrm{M}_{2} \mathrm{Cl}_{2}(\mathrm{~N}-\mathrm{S})_{2}$. Complexes $\mathrm{MX}_{2}(\mathrm{~N}-\mathrm{SMe})$ and $\left[\mathrm{M}(\mathrm{N}-\mathrm{SMe})_{2}\right]\left(\mathrm{ClO}_{4}\right)_{2}(\mathrm{M}=\mathrm{Pd}$, $\mathrm{Pt}, \mathrm{Cu}, \mathrm{Hg}$ ) were derived with 2-(2-methylthioethyl)pyridine [10] and 2-methylthiomethylpyridine [11]. The structural, spectroscopic, and biological studies of alkylthioalkylated anilines and their copper complexes are less investigated in comparison to their sulfonamide analogues. Copper ions are biologically relevant in living systems as $\mathrm{Cu}(\mathrm{I}) / \mathrm{Cu}$ (II) cuproproteins which transport molecular oxygen and act as good catalysts in related oxidation-reduction processes. Here, the spectral, structural, and antimicrobial properties of copper(II) complexes of 2-(methylthiomethyl)anilines are reported with the spectral property and antimicrobial activity of the complexes compared to their corresponding ligands. 


\section{Materials and Methods}

2.1. Materials and Physical Measurements. The reagents and solvents used in the experimental procedures were of analytical grade and used without further purification. The elemental analysis was carried out on Elementar Analysensysteme varioMICRO V1.6.2 GmbH. ${ }^{1} \mathrm{H}$ and ${ }^{13} \mathrm{C}$ NMR spectra of the ligands were obtained in $\mathrm{CDCl}_{3}$ relative to the residual proton in the solvent on Bruker Avance $400 \mathrm{MHz}$ NMR spectrometer. The midinfrared spectra $\left(400-4000 \mathrm{~cm}^{-1}\right)$ were determined as solids on PerkinElmer Spectrum 100 ATRFTIR spectrometer. Far-infrared spectra $\left(30-700 \mathrm{~cm}^{-1}\right)$ were obtained in nujol mulls held between polyethene discs and recorded on Perkin Elmer Spectrum 400 FTIR/FIR spectrometer. The electronic spectra $(250-1100 \mathrm{~nm})$ of ligands and complexes were measured in DMF using PerkinElmer Lambda 25 UV/VIS Spectrometer. The solid reflectance spectra of the copper complexes (300-1500 nm) were obtained on Shimadzu UV-3100 UV-VIS-NIR Spectrometer. Conductivity measurements of the complexes were taken at room temperature on AZ 86555 conductivity instrument. A Gouy balance was used to determine the room temperature magnetic moments of the powdered samples employing $\mathrm{Hg}$ (II) tetrathiocyanatocobaltate(II) as a calibrant and diamagnetic corrections were made from Pascal's constants.

2.2. Crystallographic Measurements. Crystallography data were collected at $-73^{\circ} \mathrm{C}$ using a Bruker KAPPA APEX II diffractometer equipped with a graphite monochromator and a molybdenum fine focus sealed X-ray tube as source of X-ray (Mo- $K \alpha$ radiation, $\lambda=0.71073 \AA$ ) and an Oxford Cryostream 700 system for sample temperature control. Bruker APEX II software was used for instrument control. The structures of the compounds were solved and refined using SHELXL97 software package [13-15]. Numerical absorption corrections were done and all nonhydrogen atoms were refined anisotropically. The positions and temperature parameters of the hydrogen atoms were fixed to the adjacent atoms. Diagrams and publication materials were generated using ORTEP [16]. Crystal size $(\mathrm{mm}), 0.06 \times 0.06 \times 0.17$; chemical formula (per unit cell), $\mathrm{C}_{8} \mathrm{H}_{10} \mathrm{Cl}_{2} \mathrm{CuN}_{2} \mathrm{O}_{2} \mathrm{~S}$; formula weight, 332.68; sum formula per unit cell, $\mathrm{C}_{16} \mathrm{H}_{20} \mathrm{Cl}_{4} \mathrm{Cu}_{2} \mathrm{~N}_{4} \mathrm{O}_{4} \mathrm{~S}_{2}$; formula weight, 665.40; monoclinic; $\mathrm{P} 2$ /c; unit cell parameters: $a(\AA)$ 5.5999(2), $b(\AA)$ 27.2688(9), $c(\AA)$ 7.6550(2), $\alpha\left(^{\circ}\right)$ 90.00, $\beta\left(^{\circ}\right)$ 97.8850(10), $\gamma\left(^{\circ}\right)$ 90.00; $V\left(\AA^{3}\right), 1157.89(6) ; \mathrm{Z}, 4 ; T(\mathrm{~K})$, $200(2) ; D_{\text {calc }}\left(\mathrm{Mg} / \mathrm{m}^{3}\right), 1.908$; absorption coefficient $\left(\mathrm{mm}^{-1}\right)$, 2.512; absorption correction (min., max.), 0.6705, 0.8721; $F$ (000), 668; $\theta$ range for data collection $\left({ }^{\circ}\right), 2.79-27.99$; limiting indices, $-4 \leq h \leq 7,-36 \leq k \leq 35,-10 \leq l \leq 10$; reflections collected, 11213; unique reflections $\left(R_{\text {int }}\right), 3530$ (0.0232); completeness to $\theta, 27.99$ (99.9\%); refinement method, full-matrix least-squares on $F^{2}$; data/restraints/parameters, 2798/0/162; goodness-of-fit on $F^{2}, 1.080$; final $R$ indices $[I>2 \sigma(I)]$, $R_{1}=0.0262, \mathrm{w} R_{2}=0.0576 ; R$ indices (all data), $R_{1}=0.0354$, $\mathrm{w} R_{2}=0.0601$; largest difference in peak and hole $\left(\mathrm{e}^{-3}\right)$, 0.383 and -0.337 .

2.3. Antimicrobial Susceptibility Procedure. The ligands (1af) and copper complexes (2a-f) were screened in vitro for their antibacterial activity against Staphylococcus aureus ATCC 6538, Bacillus subtilis (subsp. spizizenii) ATCC 6633, and Escherichia coli ATCC 8739 and for antifungal activity against Candida albicans ATCC 2091. Ampicillin (AMP) and ketoconazole (KTZ) were, respectively, used as positive controls for the antibacterial and antifungal tests. All the growth media (Mueller Hinton agar (MHA), agar bacteriological, potato dextrose agar (PDA), and nutrient broth) were prepared in double-distilled water according to standard procedure. Sterile saline was prepared by dissolving $0.85 \mathrm{~g}$ saline in double-distilled water and making up to $100 \mathrm{~mL}$. McFarland solution (0.5 turbidity standard) was prepared by adding $0.5 \mathrm{~mL}$ of $1 \%$ barium chloride to $99.5 \mathrm{~mL}$ of $1 \%$ sulphuric acid [17]. Agar disc diffusion method was employed to determine the susceptibility of the microorganisms to the test compounds $[18,19]$. The preparation of the agar plates, culturing of the microbial strains, and the inoculation of the plates followed described procedure $[20,21]$. Each microbial inoculum was standardized by reference to $0.5 \mathrm{McF}$ arland turbidity standard [17]. Stock solutions $(100 \mathrm{mg} / \mathrm{mL})$ of ampicillin and ketoconazole were also prepared and diluted to lower concentrations [21].

2.3.1. Agar Disc Diffusion Method. The sterile assay disks were kept in sealed containers at $5^{\circ} \mathrm{C}$ and allowed to equilibrate to room temperature before use. The test compounds, namely, ligands (1a-2f) and complexes (2a-2f) were dissolved in DMF. Known concentrations of test solutions were delivered on to sterile assay disks of $6 \mathrm{~mm}$ diameter each using a micropipette; the quantity taken was $250 \mu \mathrm{g}$ per disc. $125 \mu \mathrm{g}$ of Ampicillin and ketoconazole was measured on separate disks and allowed to dry under the laminar flow. Six disks were placed on each inoculated agar plate containing the appropriate growth medium and incubated for $24 \mathrm{~h}$ (bacteria) and $60 \mathrm{~h}$ (fungus) at $37^{\circ} \mathrm{C}$. The diameter of zone of inhibition of the microbial growth by each compound was thereafter measured. The tests were carried out in triplicate and the mean values are recorded in Table 5.

2.4. Synthesis of Ligands and Complexes. The ligands, 4-R-2-(methylthiomethyl)anilines (1a-1f), were prepared according to reported procedure [2]. Appropriate aniline $(10.7 \mathrm{mmol})$ and dimethyl sulfide $(15.00 \mathrm{mmol})$ in dichloromethane were vigorously stirred at room temperature. $N$-chlorosuccinimide $(15.0 \mathrm{mmol})$ was added in small portions. The mixture was stirred for $10 \mathrm{~min}$; triethylamine $(15.0 \mathrm{mmol})$ was added and the mixture was heated at reflux for $12 \mathrm{~h}$. The organic layer was extracted with $10 \%$ $\mathrm{NaOH}(25 \mathrm{~mL})$ and dried over anhydrous magnesium sulfate. Solvent was removed in vacuo to give the crude which was purified by column chromatography on silica gel 60 (0.040$0.063 \mathrm{~mm})$ using hexane: ether $(4: 1 \mathrm{vol} / \mathrm{vol})$ as the eluent. Fractions were collected in test tubes in $30 \mathrm{~mL}$ portions and $R_{f}$ value of each fraction was determined on TLC plate (silica gel $60 \mathrm{~F}_{254}$ ). Fractions with similar $R_{f}$ values were combined and dried in vacuo to remove the solvent and the NMR spectra obtained to identify the desired product (Scheme 1).

The copper(II) complexes (2a-2f) were prepared by adding equimolar amounts of cupric chloride dihydrate 


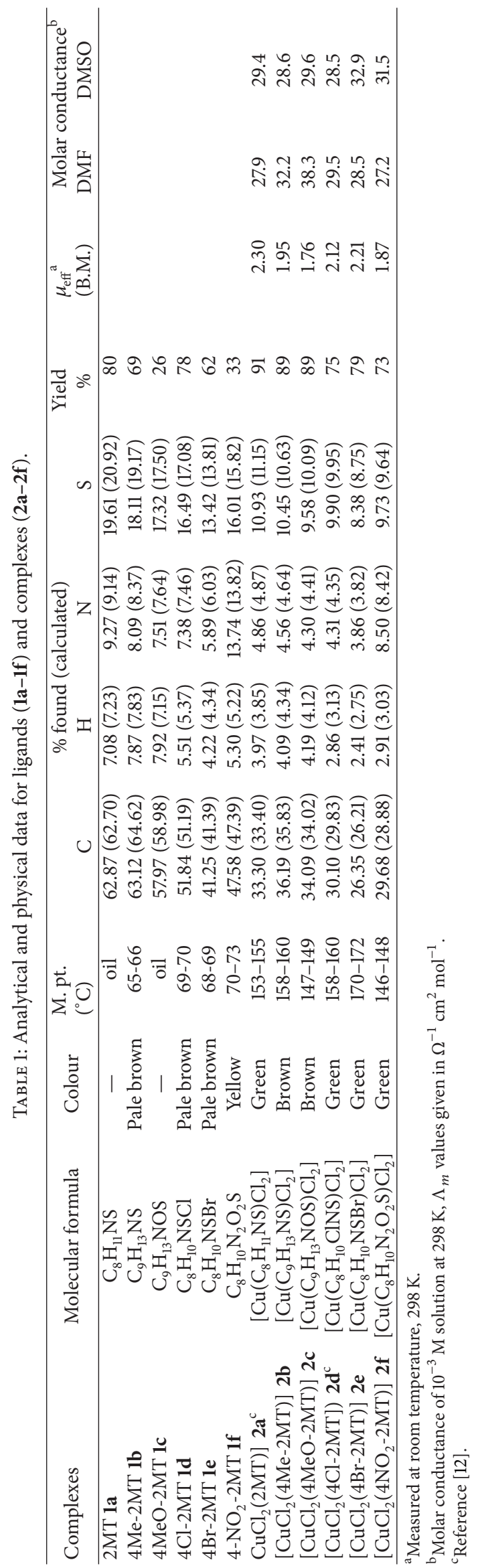




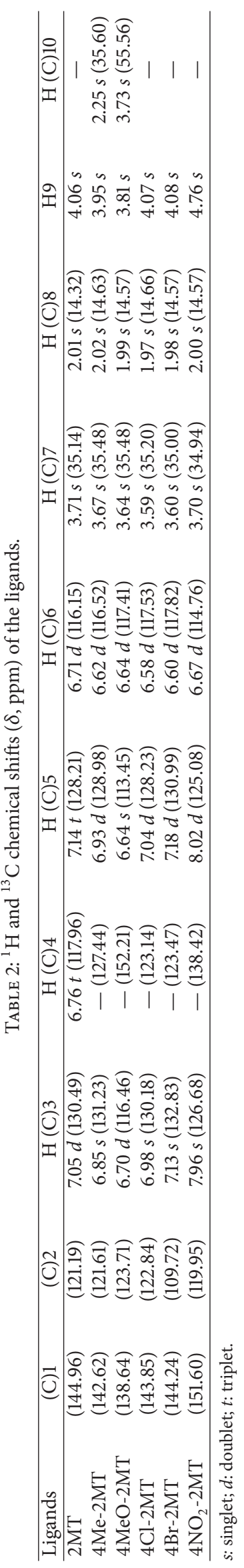


TABLE 3: Selected IR bands and the electronic spectra of the ligands and complexes.

\begin{tabular}{|c|c|c|c|c|c|c|}
\hline Compound & $v_{(\mathrm{N}-\mathrm{H})}$ & $\delta_{\mathrm{NH} 2}$ & $v_{(\mathrm{C}-\mathrm{N})}$ & $v_{(\mathrm{Cu}-\mathrm{L})}\left(\mathrm{cm}^{-1}\right)$ & Elec & nic spectra ${ }^{\mathrm{a}} \lambda_{\max }, \mathrm{nm}\left(\varepsilon, \mathrm{mol}^{-1} \mathrm{dm}^{3} \mathrm{~cm}^{-1}\right)$ \\
\hline $\mathrm{L}-\mathrm{H}(\mathbf{1 a})$ & 3424,3352 & 1618 & 1272 & & & 259,300 \\
\hline \multirow[t]{2}{*}{$2 a$} & 3294,3217 & 1609 & 1251 & $430,398,364,327,295,274$ & & $259,298,322,430,925$ \\
\hline & & & & & Solid & $353,400,706$ \\
\hline $\mathrm{L}-\mathrm{CH}_{3}(\mathbf{l b})$ & 3420,3346 & 1625 & 1275 & & & 259,306 \\
\hline \multirow[t]{2}{*}{$2 \mathrm{~b}$} & 3276,3221 & 1599 & 1259 & $446,405,335,321,294,268$ & & $259,303,330,430,916$ \\
\hline & & & & & Solid & $354,450,754$ \\
\hline $\mathrm{L}-\mathrm{OCH}_{3}(\mathbf{1 c})$ & 3409,3341 & 1626 & 1293 & & & $259,319,360$ \\
\hline \multirow[t]{2}{*}{$2 \mathrm{c}$} & 3256,3202 & 1617 & 1272 & $430,364,338,303,271$ & & $259,286,336,447,595,885$ \\
\hline & & & & & Solid & $352,403,479,786$ \\
\hline $\mathrm{L}-\mathrm{Cl}(\mathbf{1 d})$ & 3399,3307 & 1625 & 1275 & & & 275,316 \\
\hline \multirow[t]{2}{*}{$2 d$} & 3261,3221 & 1609 & 1244 & $439,398,322,297,272$ & & $261,309,335,430,936$ \\
\hline & & & & & Solid & $364,405,782$ \\
\hline $\mathrm{L}-\mathrm{Br}(\mathbf{1 e})$ & 3398,3317 & 1624 & 1275 & & & 272,312 \\
\hline \multirow[t]{2}{*}{$2 \mathrm{e}$} & 3259,3219 & 1607 & 1244 & $437,393,341,322,293,281$ & & $262,308,333,430,920$ \\
\hline & & & & & Solid & $348,425,795$ \\
\hline $\mathrm{L}-\mathrm{NO}_{2}(\mathbf{l f})$ & 3450,3347 & 1639 & 1278 & & & $258,295,392$ \\
\hline \multirow[t]{2}{*}{$2 \mathrm{f}$} & 3267,3222 & 1620 & 1250 & $425,380,365,323,294,271$ & & $263,301,381,399,428,925$ \\
\hline & & & & & Solid & $367,450,765$ \\
\hline
\end{tabular}

${ }^{\mathrm{a}}$ In DMSO.

${ }^{\mathrm{b}} \mathrm{CT}$ : charge transfer.

TABLE 4: Selected bond lengths $[\AA]$ and angles $\left[^{\circ}\right]$ for $\left[\mathrm{CuCl}_{2}\left(4 \mathrm{NO}_{2}\right.\right.$ 2MT)] (2f).

\begin{tabular}{|c|c|c|c|}
\hline Cul-N1 & $2.0750(18)$ & $\mathrm{Cul-S1}$ & $2.3214(6)$ \\
\hline Cul-Cl1 & $2.2554(6)$ & $\mathrm{Cu} 1-\mathrm{Cl} 2^{*}$ & $2.3184(5)$ \\
\hline $\mathrm{Cu} 1-\mathrm{Cl} 2^{* *}$ & $2.6902(5)$ & $\mathrm{Cl} 2-\mathrm{Cu}^{* * *}$ & $2.9321(5)$ \\
\hline S1-C8 & $1.798(2)$ & S1-C7 & $1.817(2)$ \\
\hline $\mathrm{N} 1-\mathrm{Cl}$ & $1.434(3)$ & $\mathrm{C} 4-\mathrm{N} 2$ & $1.464(3)$ \\
\hline $\mathrm{N} 2-\mathrm{O} 2$ & $1.203(3)$ & $\mathrm{N} 2-\mathrm{O} 1$ & $1.212(3)$ \\
\hline N1-Cu1-Cl1 & $176.82(5)$ & $\mathrm{Cl} 2-\mathrm{Cu} 1-\mathrm{S} 1$ & $163.90(2)$ \\
\hline S1-Cu1-Cl2 & 105.455(19) & N1-Cu1-Cl2 & $85.39(6)$ \\
\hline N1-Cu1-Cl2 & $88.60(5)$ & $\mathrm{Cl1}-\mathrm{Cu} 1-\mathrm{Cl} 2$ & $93.19(2)$ \\
\hline $\mathrm{Cl1}-\mathrm{Cu} 1-\mathrm{Cl} 2$ & $94.27(2)$ & $\mathrm{Cl} 2-\mathrm{Cu} 1-\mathrm{Cl} 2$ & $90.625(17)$ \\
\hline N1-Cu1-S1 & $91.93(5)$ & Cl1-Cul-S1 & $85.69(2)$ \\
\hline $\mathrm{Cul}-\mathrm{Cl} 2-\mathrm{Cul}$ & $89.376(17)$ & C8-S1-C7 & $102.40(11)$ \\
\hline C8-S1-Cu1 & $105.25(9)$ & C7-S1-Cu1 & $104.90(7)$ \\
\hline C1-N1-Cu1 & $118.59(13)$ & $\mathrm{O} 2-\mathrm{N} 2-\mathrm{O} 1$ & $122.3(2)$ \\
\hline $\mathrm{O} 2-\mathrm{N} 2-\mathrm{C} 4$ & $118.5(2)$ & O1-N2-C4 & $119.2(2)$ \\
\hline
\end{tabular}

${ }^{*} x, y, z ;{ }^{* *} 1-x,-y, 1-z ;{ }^{* * *}-x,-y, 1-z$.

$(0.65 \mathrm{mmol})$ in ethanol $(2 \mathrm{~mL})$ to a stirred solution of the ligand $(0.65 \mathrm{mmol})$ in ethanol or a mixture of ethanol/dichloromethane $(2 \mathrm{~mL})$. The mixture was further stirred for $1 \mathrm{~h}$ and the resulting solid precipitates were filtered off, washed with cold ethanol, and dried under vacuum (Scheme 1).

\section{Results and Discussion}

The synthesis route for the copper complexes is shown in Scheme 1. The complexes are stable solids in air, with varying shades of green colouration, and their structures were established from their elemental analyses, infrared and electronic spectra and X-ray crystallography. The results of the elemental analysis are in good agreement with the calculated values of 1:1 metal to ligand combination for the copper complexes. The complexes are completely soluble in DMF and DMSO, partially soluble in other polar solvents such as water, acetonitrile, and methanol but are completely insoluble in nonpolar organic solvents. Low molar conductance values between 27.2 and $38.3 \Omega^{-1} \mathrm{~cm}^{2} \mathrm{~mol}^{-1}$ obtained for the complexes in DMF indicate they are nonelectrolytes [22] and the nature of chlorine to metal bonds can be described as coordinative. The summary of the analytical data and other physical properties of the complexes are recorded in Table 1.

3.1. NMR Spectra. The NMR shifts for the protons and carbon atoms of the respective ligands are shown in (Scheme 2, Table 2). The proton NMR spectra of the ligands can be classified into three distinct classes; the thiomethyl $\left(-\mathrm{CH}_{3}\right)$ and methylene $\left(-\mathrm{CH}_{2}\right)$ protons appear as singlet peaks and resonate in the ranges $1.97-2.02 \delta$ and $3.59-3.70 \delta$, respectively. The broad singlet peaks found between 3.81 and $4.76 \delta$ are due to amine $\left(-\mathrm{NH}_{2}\right)$ protons and the peaks downfield in the region $6.58-7.96 \delta$ which appear as multiplets are due to the aromatic protons. The ligands with the methyl or methoxy group show additional singlet peak due to methyl $\left(-\mathrm{CH}_{3}\right)$ protons at $2.25 \delta$ or methoxy $\left(-\mathrm{OCH}_{3}\right)$ protons at $3.73 \delta$.

3.2. Infrared Spectra. Selected infrared bands of the ligands and copper complexes are recorded in Table 2. The vibrational frequencies in the $2 \mathrm{MT}$ ligands (1a-1f) were 
TABLE 5: Agar disk diffusion test of compounds against microbial strains.

\begin{tabular}{|c|c|c|c|c|}
\hline \multirow{2}{*}{ Compound } & \multicolumn{4}{|c|}{ Diameter of zones ${ }^{\mathrm{a}}$ of inhibition $(\mathrm{mm})$} \\
\hline & B. subtilis & S. aureus & E. coli & C. albicans \\
\hline la & 7 & 8 & $\mathrm{NI}^{\mathrm{b}}$ & $\mathrm{NI}$ \\
\hline $2 a$ & 14 & 10 & 7 & 9 \\
\hline $1 \mathbf{b}$ & 8 & 8 & 7 & NI \\
\hline $2 b$ & 13 & 10 & 8 & 9 \\
\hline $1 \mathrm{c}$ & 12 & 13 & 7 & NI \\
\hline $2 c$ & 18 & 20 & 7 & 13 \\
\hline 1d & 8 & 8 & 7 & NI \\
\hline $2 d$ & 9 & 8 & 7 & 10 \\
\hline le & 9 & 8 & 7 & NI \\
\hline $2 \mathrm{e}$ & 9 & 9 & 7 & 11 \\
\hline If & 9 & 7 & 7 & NI \\
\hline $2 f$ & 10 & 8 & 7 & NI \\
\hline AMP $125 \mu \mathrm{g} /$ disk & 40 & 38 & 23 & - \\
\hline KTZ $125 \mu \mathrm{g} /$ disk & - & - & - & 23 \\
\hline $\mathrm{CuCl}_{2} \cdot 2 \mathrm{H}_{2} \mathrm{O}$ & 8 & 8 & 7 & 8 \\
\hline DMF & 6 & 6 & 6 & 6 \\
\hline
\end{tabular}

${ }^{\mathrm{a}} 250 \mu \mathrm{g} \mathrm{disc}{ }^{-1}$ sample concentration, disc diameter $6 \mathrm{~mm}$.

${ }^{\mathrm{b}}$ NI: No inhibition.

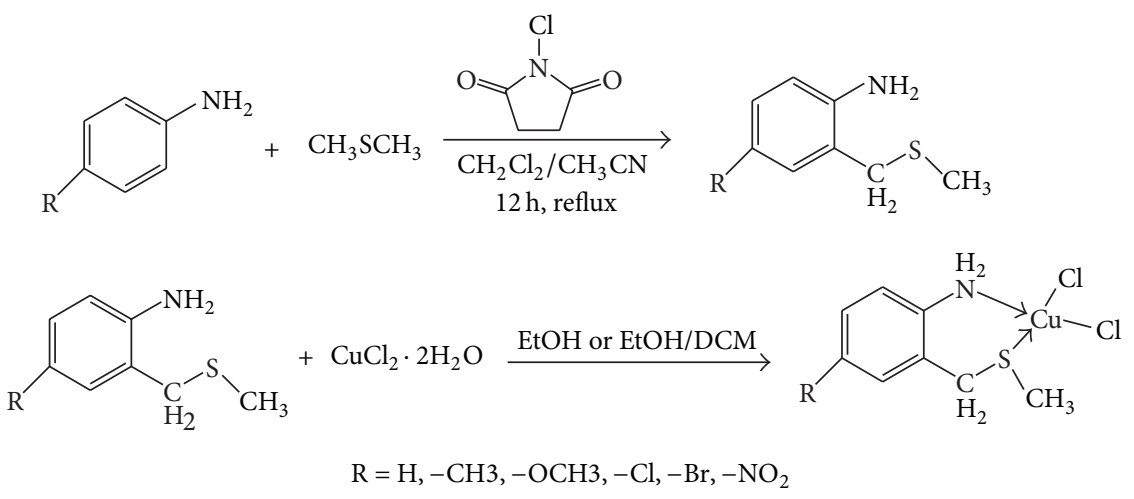

Scheme 1: Synthesis of ligands (1a-1f) and copper complexes (2a-2f).

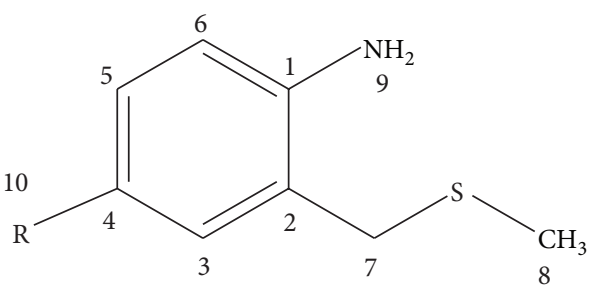

$\mathrm{R}=\mathrm{H}, \mathrm{Me}, \mathrm{MeO}, \mathrm{Cl}, \mathrm{Br}, \mathrm{NO}_{2}$

Scheme 2: Labelling arrangement of ${ }^{1} \mathrm{H}$ and ${ }^{13} \mathrm{C}$ chemical shifts $(\delta)$ of ligands (1a-1f) in ppm.

characterized by those observed in primary amines [23]. The $\mathrm{N}-\mathrm{H}$ symmetric and asymmetric stretches were found between 3320 and $3400 \mathrm{~cm}^{-1}$, respectively; $\mathrm{NH}_{2}$ scissor was in the range $1590-1600 \mathrm{~cm}^{-1}$ and $\mathrm{C}-\mathrm{N}$ stretching frequency was seen around $1280 \mathrm{~cm}^{-1}$. The band expected from the thioether group due to $\mathrm{C}-\mathrm{S}-\mathrm{C}$ bend (around $1100 \mathrm{~cm}^{-1}$ ) and that due to C-S stretch between 650 and $780 \mathrm{~cm}^{-1}$ was not observed as they are weak bands and were masked by vibrations associated with the benzene ring [24]. There was no deprotonation of the amine hydrogen atoms upon complexation as two $\mathrm{N}-\mathrm{H}$ stretches were observed, shifted to lower energies by $100-200 \mathrm{~cm}^{-1}$. The $\mathrm{N}-\mathrm{H}$ bends were similarly shifted to lower frequencies $\left(\mathrm{cm}^{-1}\right)$ in the complexes. The shift to lower frequency of these vibrational modes after chelation is a result of the electron density of the nitrogen being directed to the metal ion, leaving the amino protons less tightly bound to the nitrogen [25]. Copper to ligand vibrations were seen in the far infrared region; $v \mathrm{Cu}-\mathrm{N}$ was observed in the range $425-450 \mathrm{~cm}^{-1}[26]$ and the vibrations due to $\mathrm{Cu}-\mathrm{Cl}$ stretches consist of a mixture of medium and intense bands in the complexes between 268 and $365 \mathrm{~cm}^{-1}[27,28]$. In the crystal structure of complex (2f) below, the arrangement of the ligand atoms around the $\mathrm{Cu}^{2+}$ center includes two chloride ions, one of them terminally 


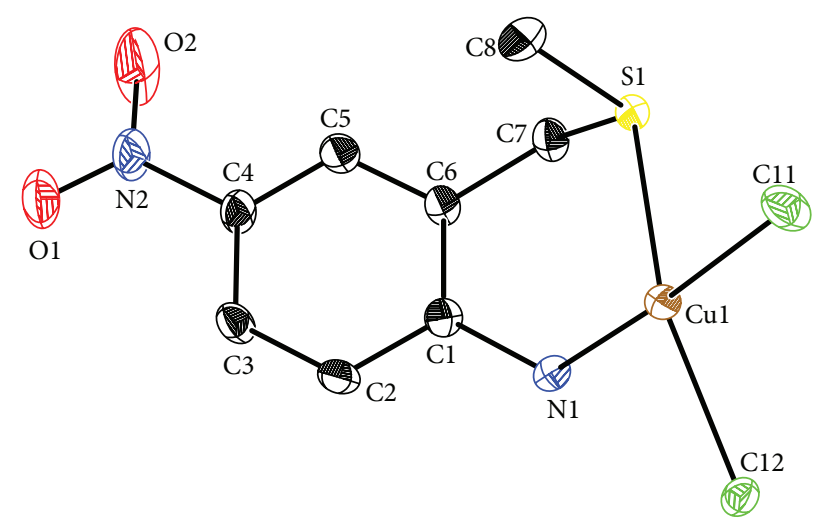

Figure 1: Monomer unit of $\left[\mathrm{CuCl}_{2}\left(4 \mathrm{NO}_{2}-2 \mathrm{MT}\right)\right]$ 2f. Ellipsoids drawn at $50 \%$ probability and hydrogen atoms are omitted for clarity.

bonded, while the other is linked to two other adjacent copper centres in a bridging mode. Frequencies between 268 and $303 \mathrm{~cm}^{-1}$ are assigned as $v \mathrm{Cu}-\mathrm{Cl}$ for equatorial bonds [29]. Bands close to $320 \mathrm{~cm}^{-1}$ were assigned to $\mathrm{Cu}-\mathrm{S}$ stretches [30].

3.3. The Crystallographic Structure of $\left[\mathrm{Cu}\left(4 \mathrm{NO}_{2}-2 \mathrm{MT}\right)\right](\mathbf{2 f})$. A single crystal of (2f) was grown by the slow evaporation of a mixture of DMSO/EtOH solution $(2: 1 \mathrm{vol} / \mathrm{vol})$. The atom numbering scheme and the selected bond distances and angles are listed in Table 3. The four corners of the square plane of (2f) are occupied by the aniline nitrogen (N1), thioether sulfur (S1), and two chloride ions (Cl1, Cl2) which have cis arrangement to each other. One chlorido ligand (Cl1) is terminally bonded, while the other $(\mathrm{Cl} 2)$ is bonded to two other copper ions in adjacent molecules as a bridging ligand giving rise to an octahedral arrangement around each copper center. Hence the complex has a monomer formula of $\mathrm{CuLCl}_{2}$ (where $\mathrm{L}$ is the ligand) and the ORTEP drawing is shown in Figure 1. The presence of chloride bridges between the adjacent molecules results in a "ladder-like" polymeric structure seen in Figure 2. The bond distances for Cu1-N1 and Cul-S1 which are 2.075(18) and 2.321(6) $\AA$, respectively, fall within the expected ranges $[31,32]$ and the Cul-S1 distance is typical of equatorially bound thioether sulfur [33-40]. $\mathrm{Cu}-\mathrm{Cl}$ lengths are observed at 2.255(6) $\AA$ (Cu1-Cl1 terminal bond), 2.318(5) $\AA$ (Cu1-Cl2 in the basal bond), 2.690(5) $\AA$ (Cu1$\mathrm{Cl} 2$ bridging bond), and 2.932(5) $\AA$ (Cul-Cl2 bridging bond). The longer distances observed for $\mathrm{Cul}-\mathrm{Cl} 2$ bonds are within the acceptable range for $\mathrm{Cu}-\mathrm{Cl}$ distances for axial bonds in previously reported copper(II) octahedral compounds $[32,41-43]$. The $\mathrm{Cu}-\mathrm{Cu}$ distance of $3.532 \AA$ is normal for distorted octahedral structures [25]. The bond angles for the basal ligands trans to each other are $176.82^{\circ}$ and $163.90^{\circ}$ for N1-Cu1-Cl1 and S1-Cu1-Cl2, respectively. L(basal)-Cu$\mathrm{L}$ (apical) angles which are ideally $90^{\circ}$ range from $85.39^{\circ}$ to $105.45^{\circ}$, the greater deviation being from S1-Cul-Cl2 bond angle.

3.4. Magnetic Moment and Electronic Spectra. The magnetic moments of copper(II) complexes (2a-2f) are recorded in Table 1. The magnetic moments between 1.76 and $2.30 \mathrm{~B}$. M. obtained for the complexes suggest the presence of one electron in the $\mathrm{d}^{9}$ copper(II) configuration. The increase from the spin-only value of $1.73 \mathrm{~B}$. M could be due to spin orbit coupling or orbital contribution from the unpaired electron in the ground state [44]. The electronic spectra of the ligands and copper(II) complexes in DMSO are recorded in Table 2. The spectra of the ligands (1a-1f) consist of two high energy bands found in the range $250-320 \mathrm{~nm}$ arising from $\pi \rightarrow \pi^{*}$ transitions of the phenyl ring; the ligands (1c) and (1f) show an additional band close to 360 and $390 \mathrm{~nm}$, respectively, due to intraligand charge transitions of their methoxy and nitro groups. The electronic spectra of the copper(II) complexes in DMSO similarly show the $\pi \rightarrow \pi^{*}$ transitions which are slightly shifted to shorter wavelengths as a result of decrease in conjugation of the system after complexation. Ligand to metal charge transfer transitions are observed; the band in the region $320-390 \mathrm{~nm}$ is assigned as $\mathrm{N} \rightarrow \mathrm{Cu}$, while that between 400 and $450 \mathrm{~nm}$ is associated with $\mathrm{S}(\sigma) \rightarrow \mathrm{Cu}$ [25]. In the solid reflectance spectra of the complexes in Figure 3(a), two high energy bands due to charge transfer transitions are found near 350 and $400 \mathrm{~nm}$, while the broad band in the range 700$800 \mathrm{~nm}$ is assigned to $\mathrm{d} \rightarrow \mathrm{d}$ transition [25]. The description of the $\mathrm{d} \rightarrow \mathrm{d}$ band of the complexes changes in DMSO (Figure 3(b)) and a broad low-energy band is observed in the near-infrared between 880 and $920 \mathrm{~nm}$. The shift to lower energies, by approximately $100 \mathrm{~nm}$, is indicative of geometry change in the complexes as a result of probable coordination of DMSO to copper(II). From the crystal structure, the $\mathrm{Cu}-$ $\mathrm{Cl}$ distance in the bridging bonds is long and could imply a possible replacement of the axial binding site through the bridging chlorido ligand by the high coordinating DMSO molecule. Previous studies on electronic spectra of similar copper(II) complexes in DMF suggested the coordination of the solvent molecule to the metal ion resulting in distorted octahedral or tetragonal structures [19]. The large bandwidth in the electronic spectra can be attributed to Jahn-Teller distortion which is commonly observed in octahedral $\mathrm{Cu}$ (II) complexes.

3.5. Antimicrobial Susceptibility Testing. The results for the disc diffusion susceptibility tests recorded in Table 4 shows the inhibitory activity of each ligand was improved upon chelation to copper ion. The higher activity of the complexes could be due to the increased lipophilicity conferred on the complex by the copper ion. It was also observed that the pure metal salt solution has an inhibitory effect on the microbial growth and it shows a measure of biological activity. In this study, the gram-positive bacteria were more susceptible to the test compounds than the gram-negative E. coli and the fungus $C$. albicans. Among the ligands and complexes screened, those with electron donating groups are seen to inhibit the microbial growth better than the electron withdrawing groups. The compounds with the methoxy moiety (1c) and (2c) demonstrate more inhibitory activity than other compounds (2b) with a methyl group showing a similar though less pronounced activity.

\section{Conclusion}

The copper(II) complexes (2a-2f) formed in a 1:1 ligand to metal reaction stoichiometry and were characterized by the 


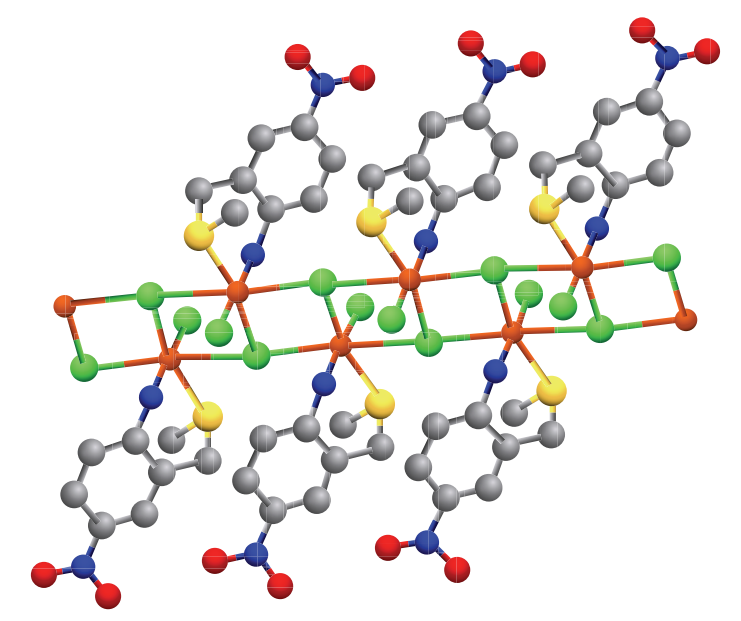

Figure 2: Ladder-like polymeric octahedral structure of $\left[\mathrm{CuCl}_{2}\left(4 \mathrm{NO}_{2}-2 \mathrm{MT}\right)\right] \mathbf{2 f}$. C, grey; $\mathrm{Cl}$, green; $\mathrm{Cu}$, wine; $\mathrm{N}$, blue; $\mathrm{O}$, red; S, yellow.

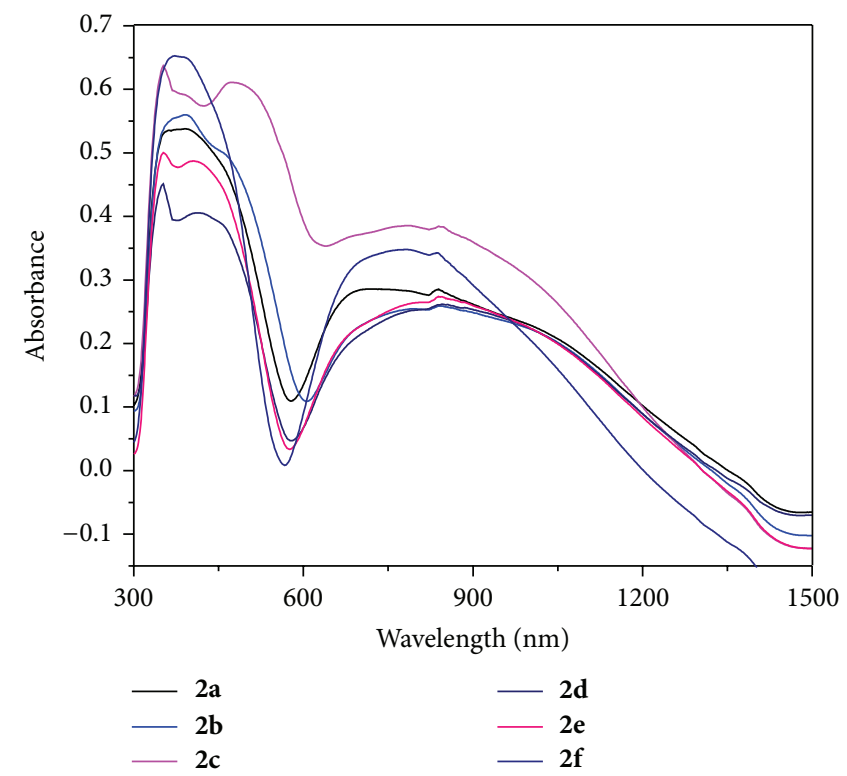

(a)

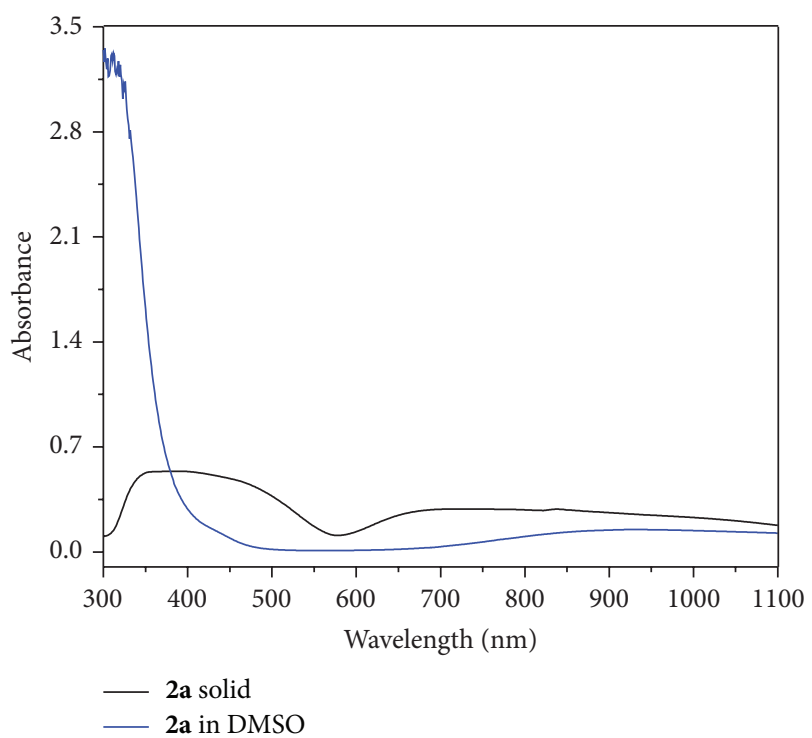

(b)

FIGURE 3: Solid reflectance spectra of $\mathbf{2 a - 2 f}$ (a), complex 2a compared with its solution spectrum in DMSO (b).

elemental analysis, IR and X-ray crystallography. A change in the structure of the complexes in the solid state is suspected as a result of the coordination of DMSO to the copper(II). Screening of the ligands and their copper complexes for in vitro antimicrobial activity against $S$. aureus, B. subtilis, E. coli, and $C$. albicans was carried out using agar disk diffusion as well as microbroth dilution techniques. The methoxy complex (2c) showed promising antibacterial activityagainst $S$. aureus and B. subtilis, while E. coli was not susceptible to any of the compounds at the concentration tested.

\section{Extra Material}

CCDC 888074 contains the supplementary crystallographic data for compound $\left[\mathrm{CuCl}_{2}\left(4 \mathrm{NO}_{2}-2 \mathrm{MT}\right)\right]$ (2f) (see Suppl- ementary Material available online at http://dx.doi.org/ 10.1155/2014/769573). Copies of these data can be obtained free of charge from the Cambridge Crystallographic Data Centre via http://www.ccdc.cam.ac.uk/data_request/cif/.

\section{Conflict of Interests}

The authors declare that there is no conflict of interests.

\section{Acknowledgments}

One of the authors (Temitope E. Olalekan) thanks the Organization of Women in Science for the Developing World (OWSDW) for providing a Research Fellowship and Rhodes University for academic bursary. 


\section{References}

[1] H. L. Holland, F. M. Brown, A. Kerridge, and C. D. Turner, "Biotransformation of organic sulfides. Part. 10. Formation of chiral ortho- and meta-substituted benzyl methyl sulfoxides by biotransformation using Helminthosporium species NRRL 4671," Journal of Molecular Catalysis B: Enzymatic, vol. 6, no. 5, pp. 463-471, 1999.

[2] J. P. Chupp, T. M. Balthazor, M. J. Miller, and M. J. Pozzo, “Behavior of benzyl sulfoxides toward acid chlorides. Useful departures from the Pummerer reaction," Journal of Organic Chemistry, vol. 49, no. 24, pp. 4711-4716, 1984.

[3] P. G. Gassman and H. R. Drewes, "Selective ortho formylation of aromatic amines," Journal of the American Chemical Society, vol. 96, no. 9, pp. 3002-3003, 1974.

[4] J. Whysner, L. Verna, and G. M. Williams, "Benzidine mechanistic data and risk assessment: species- and organ-specific metabolic activation," Pharmacology and Therapeutics, vol. 71, no. 1-2, pp. 107-126, 1996.

[5] H. Stunzi, "Can chelationbe important in the antiviral activity of isatin $\beta$-thiosemicarbazones?" Australian Journal of Chemistry, vol. 35, no. 6, pp. 1145-1155, 1982.

[6] M. J. M. Campbell, "Transition metal complexes of thiosemicarbazide and thiosemicarbazones," Coordination Chemistry Reviews, vol. 15, no. 2-3, pp. 279-319, 1975.

[7] S. Padhyé and G. B. Kauffman, "Transition metal complexes of semicarbazones and thiosemicarbazones," Coordination Chemistry Reviews, vol. 63, pp. 127-160, 1985.

[8] L. F. Lindoy, S. E. Livingstone, and T. N. Lockyer, "S-dealkylation and S-alkylation reactions of metal chelates of sulfur ligands," Inorganic Chemistry, vol. 6, no. 4, pp. 652-656, 1967.

[9] L. F. Lindoy, S. E. Livingstone, and T. N. Lockyer, "Sulphurnitrogen chelating agents. I. Metal complexes of 8-methylthioquinoline," Australian Journal of Chemistry, vol. 19, no. 8, pp. 1391-1400, 1966.

[10] P. S. K. Chia, S. E. Livingstone, and T. N. Lockyer, "Sulphurnitrogen chelating agents. II. Metal complexes of 2-(2methylthioethyl)pyridine," Australian Journal of Chemistry, vol. 19, no. 10, pp. 1835-1845, 1966.

[11] P. S. K. Chia, S. E. Livingstone, and T. N. Lockyer, "Sulphur-nitrogen chelating agents. III. Metal complexes of 2-(methylthiomethyl)pyridine," Australian Journal of Chemistry, vol. 20, no. 2, pp. 239-255, 1967.

[12] K. Kratzl, H. Fostel, and R. Sobczak, "Metallkomplexe einiger o-methylthiomethyaniline (metal complexes of o-methylthiomethylaniline)," Monatshefte für Chemie, vol. 9, no. 103, p. 677, 1972.

[13] G. M. Sheldrick, "A short history of SHELX," Acta Crystallographica A: Foundations of Crystallography, vol. 64, no. 1, pp. 112-122, 2007.

[14] G. M. Sheldrick, "Crystal structure refinement incorporating chemical information," in Electron Crystallography, D. L. Dorset, S. Hovmöller, and X. Zou, Eds., vol. 347 of NATO ASI Series, pp. 219-220, 1997.

[15] G. M. Sheldrick and T. R. Schneider, "SHELXL: high-resolution refinement," Methods in Enzymology, vol. 277, pp. 319-343, 1997.

[16] L. J. Farrugia, "ORTEP-3 for windows-a version of ORTEPIII with a graphical user interface (GUI)," Journal of Applied Crystallography, vol. 30, no. 5, p. 565, 1997.

[17] J. McFarland, “The nephelometer: an instrument for estimating the number of bacteria in suspensions used for calculating the opsonic index and for vaccines," Journal of American Medical Association, vol. 49, no. 14, pp. 1176-1178, 1907.

[18] A. W. Bauer, W. M. Kirby, J. C. Sherris, and M. Turck, "Antibiotic susceptibility testing by a standardized single disk method," American Journal of Clinical Pathology, vol. 45, no. 4, pp. 493496, 1966.

[19] J. L. Rios, M. C. Recio, and A. Villar, "Screening methods for natural products with antimicrobial activity: a review of the literature," Journal of Ethnopharmacology, vol. 23, no. 2-3, pp. 127-149, 1988.

[20] S. M. Finegold and E. J. Baron, Bailey and Scott's Diagnostic Microbiology, C. V. Mosby Co., St. Louis, Mo, USA, 7th edition, 1986.

[21] J. H. Jorgensen and J. D. Turnidge, "Susceptibility test methods: dilution and disk diffusion methods," in Manual of Clinical Microbiology, P. R. Murray, E. J. Baron, J. H. Jorgensen, M. L. Landry, and M. A. Pfaller, Eds., vol. 1, pp. 1152-1172, American Society for Microbiology, Washington, DC, USA, 9th edition, 2007.

[22] W. J. Geary, "The use of conductivity measurements in organic solvents for the characterisation of coordination compounds," Coordination Chemistry Reviews, vol. 7, no. 1, pp. 81-122, 1971.

[23] P. J. Kruger and D. W. Smith, "Amino group stretching vibrations in primary aliphatic amines," Canadian Journal of Chemistry, vol. 45, no. 14, pp. 1611-1618, 1967.

[24] K. Nakamoto, Infrared and Raman Spectra of Inorganic and Coordination Compounds, Part I: Theory and Applications in Inorganic Chemistry, John Wiley \& Sons, New York, NY, USA, 1984.

[25] R. J. H. Clark, "Metal-halogen stretching frequencies in inorganic complexes," Spectrochimica Acta, vol. 21, no. 5, pp. 955963, 1965.

[26] J. A. Lee-Thorp, J. E. Rüede, and D. A. Thornton, "The infrared spectra $\left(3500-150 \mathrm{~cm}^{-1}\right)$ of aniline complexes of cobalt(II), nickel(II), copper(II) and zinc(II) halides," Journal of Molecular Structure, vol. 50, no. 1, pp. 65-71, 1978.

[27] I. S. Ahuja, D. H. Brown, R. H. Nuttall, and D. W. A. Sharp, “The preparation and spectroscopic properties of some aniline complexes of transition metal halides," Journal of Inorganic and Nuclear Chemistry, vol. 27, no. 5, pp. 1105-1110, 1965.

[28] G. F. Svatos, C. Curran, and J. V. Quagliano, "Infrared absorption spectra of inorganic coordination complexes. V. The N-H stretching vibration in coordination compounds," Journal of the American Chemical Society, vol. 77, no. 23, pp. 6159-6163, 1955.

[29] E. W. Ainscough, E. N. Baker, A. M. Brodie, and N. G. Larsen, "Copper co-ordination to thioether ligands. Spectroscopic studies of dimeric copper(II) complexes of 2-(3,3-dimethyl2 -thiabutyl)pyridine and the crystal structure of $\mathrm{di}-\mu$ bromo-bis\{bromo[2-(3,3-dimethyl-2-thiabutyl)pyridine-NS] copper(II))\}," Journal of the Chemical Society, Dalton Transactions, no. 10, pp. 2054-2058, 1981.

[30] K. Nakamoto, Infrared and Raman Spectra of Inorganic and Coordination Compounds, John Wiley \& Sons, New York, NY, USA, 3rd edition, 1978.

[31] L. Escriche, M. Sanz, J. Casabó, F. Teixidor, E. Molins, and C. Miravitlles, "Closely related macrocyclic and acyclic tridentate, pyridine derivatives, containing sulphur, and their com-plexes. Crystal structures of \{dichloro-3,10-dithia-16azabicyclo[10.3.1] hexadeca-1(16),12,14-triene\} copper(II) and dichlorocopper(II)," Journal of the Chemical Society, Dalton Transactions, no. 9, pp. 1739-1743, 1989. 
[32] S. B. Sanni, H. J. Behm, P. T. Beurskens et al., "Copper(II) and zinc(II) co-ordination compounds of tridentate bis(benzimidazole)pyridine ligands. Crystal and molecular structures of bis copper(II) diperchlorate monohydrate and (acetonitrile)[2,6bis(benzimidazol-2' -yl)pyridine] (perchlorato)copper(II) perchlorate," Journal of the Chemical Society, Dalton Transactions, no. 6, pp. 1429-1435, 1988.

[33] M. Vaidyanathan, R. Balamurugan, U. Sivagnanam, and M. Palaniandavar, "Synthesis, structure, spectra and redox of $\mathrm{Cu}$ (II) complexes of chelating bis(benzimidazole) - thioether ligands as models for electron transfer blue copper proteins," Journal of the Chemical Society, Dalton Transactions, no. 23, pp. 3498-3506, 2001.

[34] P. C. Burns and F. C. Hawthorne, "Tolbachite, $\mathrm{CuCl}_{2}$, the first example of $\mathrm{Cu}^{2+}$ octahedrally coordinated by $\mathrm{Cl}^{-}$," American Mineralogist, vol. 78, no. 1-2, pp. 187-189, 1993.

[35] J. G. Gilbert, A. W. Addison, A. Y. Nazarenko, and R. J. Butcher, "Copper(II) complexes of new unsymmetrical NSN thioether ligands," Inorganica Chimica Acta, vol. 324, no. 1-2, pp. 123-130, 2001.

[36] M. D. Glick, D. P. Gavel, L. L. Diaddario, and D. B. Rorabacher, "Structure of the 14-membered macrocyclic tetrathia ether complex of copper(II). Evidence for undistorted geometries in blue copper protein models," Inorganic Chemistry, vol. 15, no. 5, pp. 1190-1193, 1976.

[37] E. N. Baker and G. E. Norris, "Copper co-ordination to thioether ligands: crystal and molecular structures of bis(2,5-dithiahexane)copper(II) bis(tetrafluoroborate) and bis(3,6-dithiaoctane)copper(I) tetrafluoroborates," Journal of the Chemical Society, Dalton Transactions, no. 9, pp. 877-882, 1977.

[38] R. Louis, Y. Agnus, and R. Weiss, "Binuclear copper(II) "face to face" inclusion complex of a macrotricyclic ligand," Journal of the American Chemical Society, vol. 100, no. 11, pp. 3604-3605, 1978.

[39] B. Cohen, C. C. Ou, R. A. Lalancette, W. Borowski, J. A. Potenza, and H. J. Schugar, "Crystal and molecular structure of di- $\mu$-chloro-bis[chloro(5,8-dithiadodecane)copper(II)], $\left[\mathrm{Cu}\left(\mathrm{BuSCH}_{2} \mathrm{CH}_{2} \mathrm{SBu}\right) \mathrm{Cl}_{2}\right]_{2}$," Inorganic Chemistry, vol. 18, no. 2, pp. 217-220, 1979.

[40] G. R. Brubaker, J. N. Brown, M. K. Yoo, R. A. Kinsey, T. M. Kutchan, and E. A. Mottel, "Crystal and molecular structures of (1,8-bis(2-pyridyl)-3,6-dithiaoctane)copper(I) hexafluorophosphate and perchlorato(1,8-bis(2-pyridyl)-3,6-dithiaoctane)copper(II) perchlorate: stereodynamics of the copper(II)copper(I) couple," Inorganic Chemistry, vol. 18, no. 2, pp. 299-302, 1979.

[41] B. K. Santra, P. A. N. Reddy, M. Nethaji, and A. R. Chakravarty, "Structural model for the $\mathrm{CuB}$ site of dopamine $\beta$-hydroxylase: crystal structure of a copper(II) complex showing $\mathrm{N}_{3}$ OS coordination with an axial sulfur ligation," Inorganic Chemistry, vol. 41, no. 5, pp. 1328-1332, 2002.

[42] B. K. Santra, P. A. N. Reddy, M. Nethaji, and A. R. Chakravarty, "Structural model for the $\mathrm{CuB}$ site of dopamine $\beta$-hydroxylase and peptidylglycine $\alpha$-hydroxylating monooxygenase: crystal structure of a copper(II) complex showing $\mathrm{N}_{3}$ OS coordination and axial sulfur ligation," Journal of the Chemical Society, Dalton Transactions, no. 24, pp. 3553-3555, 2001.

[43] R. D. Willett, G. Pon, and C. Nagy, "Crystal chemistry of the 4,4' -dimethyl-2,2' bipyridine/copper bromide system," Inorganic Chemistry, vol. 40, no. 17, pp. 4342-4352, 2001.
[44] B. N. Figgis and J. Lewis, "The magneto chemistry of chelates," in Modern Coordination Chemistry, J. Lewis and R. G. Wilkins, Eds., Interscienc, New York, NY, USA, 1960. 

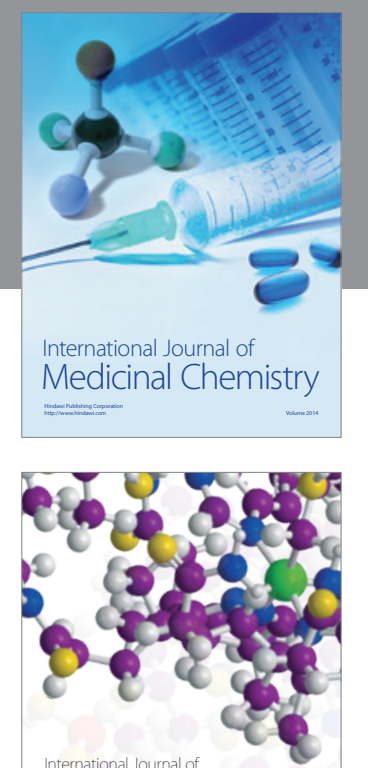

\section{Carbohydrate} Chemistry

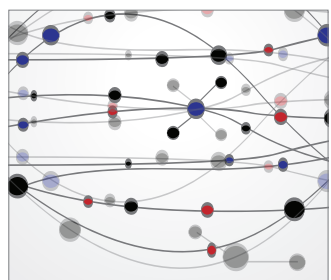

The Scientific World Journal
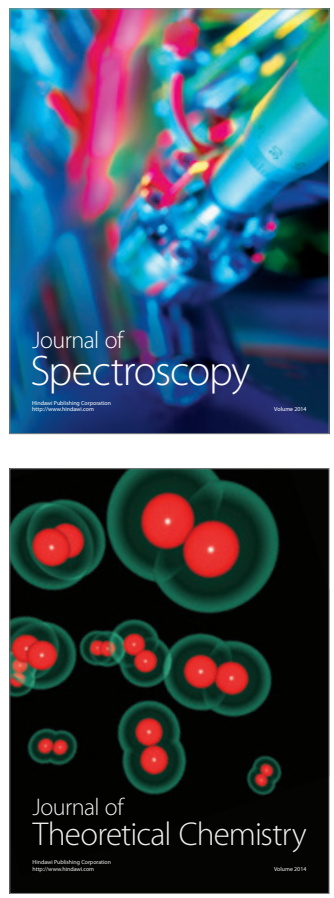
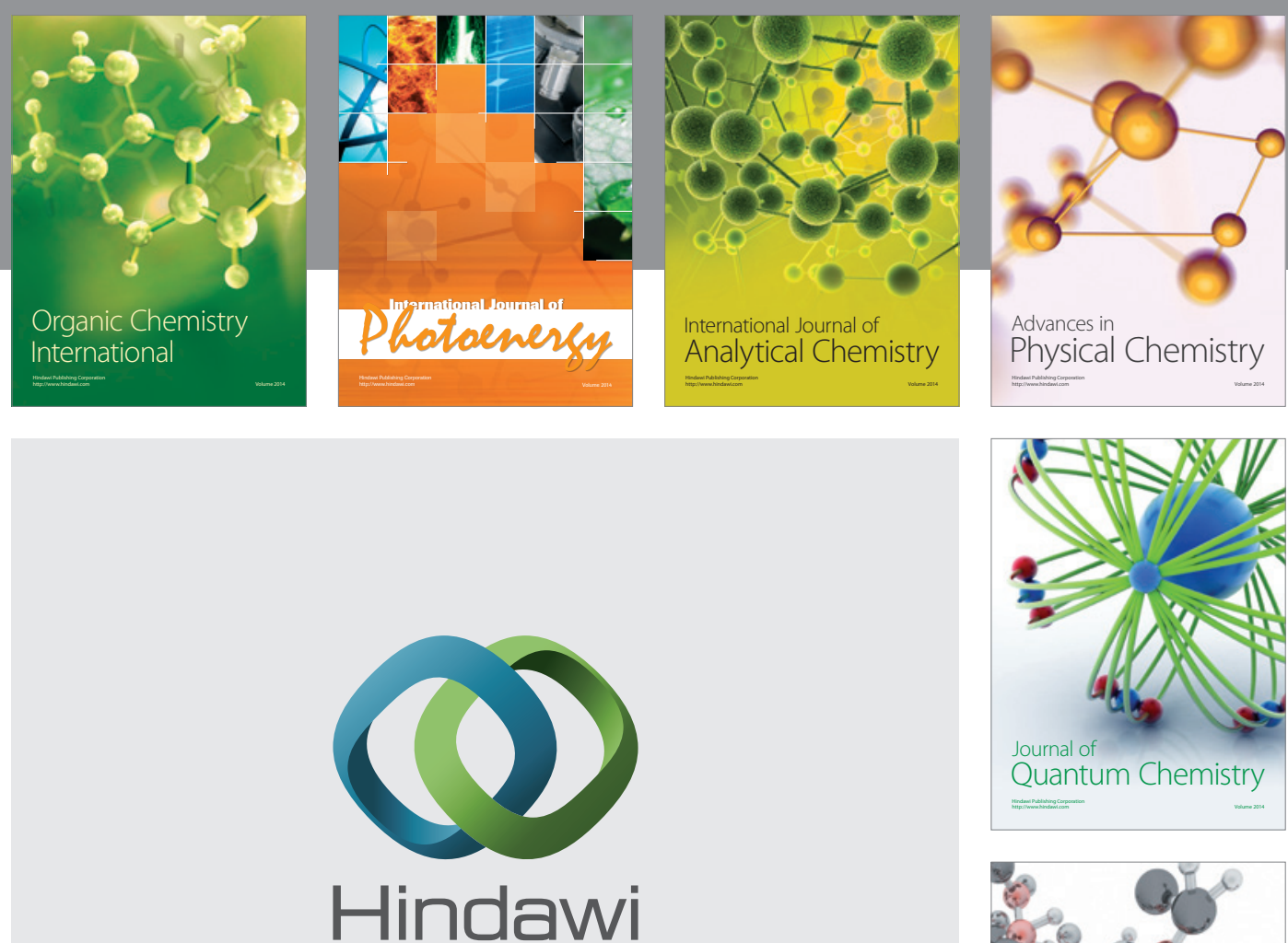

Submit your manuscripts at

http://www.hindawi.com

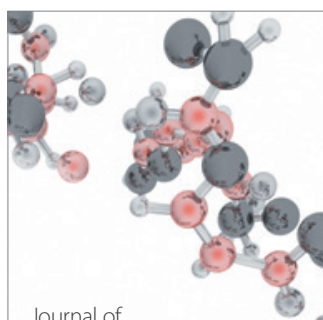

Analytical Methods

in Chemistry

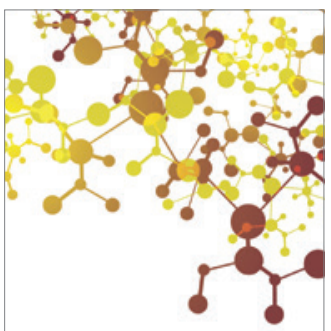

Journal of

Applied Chemistry

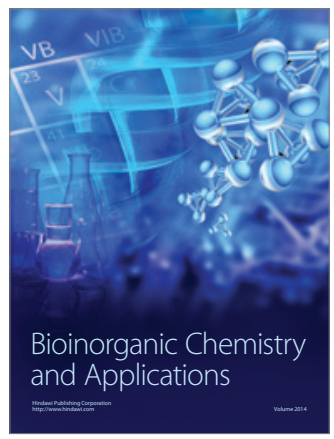

Inorganic Chemistry
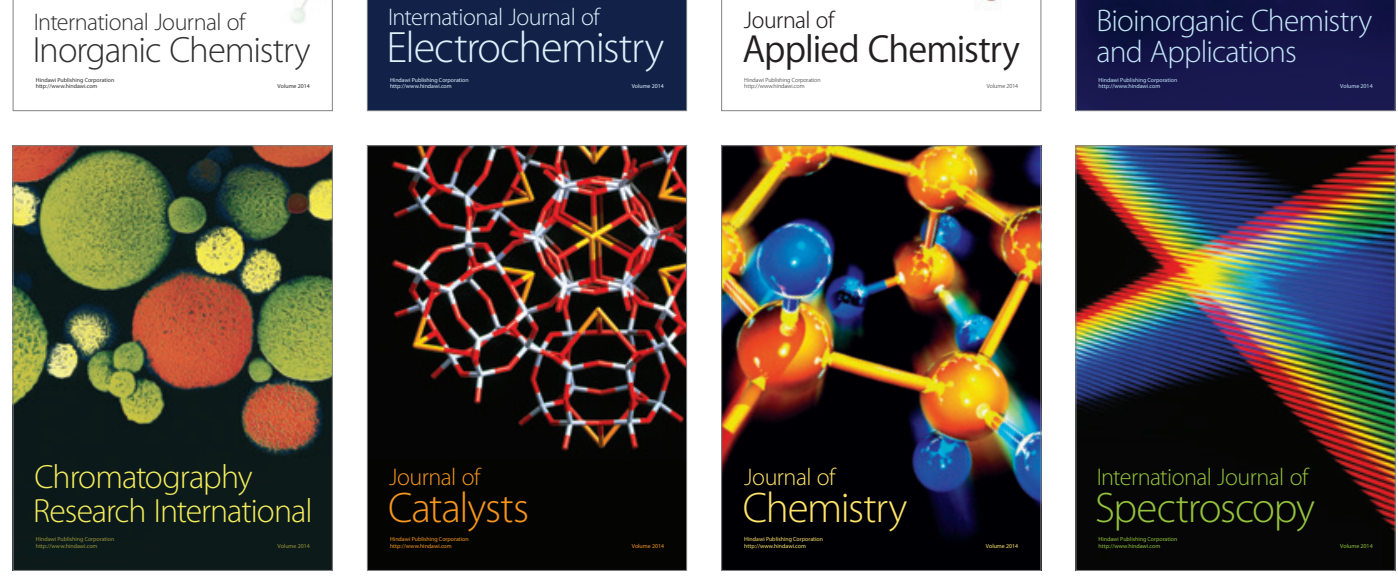